\title{
Pedoman Menentukan Daerah Cuaca Buruk Bagi Para Nakhoda
}

\author{
M. Chaeran ${ }^{a^{*}}$, Harcici ${ }^{\mathrm{b}}$ \\ ${ }^{\text {ab } U n i v e r s i t a s ~ M a r i t i m ~ A M N I ~}$ \\ a*Email :mochamadchaeran@gmail.com, \\ b) Email: cicighufron@gmail.com
}

\begin{abstract}
ABSTRAK
Kondisi cuaca saat ini mengalami perubahan yang sangat signifikan, mengingat hal tersebut tidak menutup kemungkinan bahwa masih banyak para Nakhoda sering terjebak pada daerah cuaca buruk, hal ini disebabkan masih banyak para Nakhoda tidak memperhatikan weather chart yang menggambarkan daerah cuaca buruk dan daerah cuaca cerah. Untuk itu tujuan penulisan artikel ini adalah perlunya para nakhoda mempelajari, mengetahui dan memperhatikan simbol-simbol yang menggambarkan daerah cuaca buruk sehingga diharapkan dalam berlayar tidak terjebak lagi di daerah cuaca buruk. Penelitian ini merupakan penelitian deskriptif kualitatif diman metode yang dipakai studi pustaka dan pengamatan. Hasil penelitian ini dapat diketahui bahwa setiap unsur cuaca dapat ditentukan daerah cuaca buruk tidaknya setelah digambar dalam bentuk analisa pada weather chart dengan simbol yang jelas terlihat dalam seperti daerah daerah; Low pressure $(L)$, convergence, siklonik, front. Tinggi gelombang, Kelembaban Udara.
\end{abstract}

Kata kunci: cuaca, udara, nakhoda, pelayaran

\section{PENDAHULUAN}

Kondisi cuaca dapat menentukan lancar tidaknya kegiatan pelayaran, jika cuaca buruk kegiatan pelayaran terganggu bahkan bisa terjadi musibah kecelakaan. Cuaca saat ini tidak dapat diprediksi dan sering terjadi cuaca ekstrem. Mengingat perubahan yang sangat cepat dan mendasar dengan perubahan kondisi atmosfer bumi yang terjadi dan dipengaruhi adanya perubahan kondisi lingkungan di bumi dengan bertambahnya populasi manusia dan aktifitasnya seperti penggundulan hutan, pemakaian bahan bakar dari BBM yang tidak terkendali menyebabkan pemanasan global (global warming) sehingga akan mempengaruhi perubahan cuaca secara signifikan. Hal ini akan menyebabkan banyak daerah yang cuaca buruknya meningkat baik jumlah maupun intensitasnya jika para nakhoda tidak memperhatikan simbol-simbol meteorologi daerah cuaca buruk, tidak menutup kemungkinan akan sering terjebak di daerah cuaca buruk yang membahayakan keselamatan pelayaran.

Masih sering ditemui bahwa para nakhoda dalam menjalankan kapalnya dalam perjalanan sering terjebak di daerah cuaca buruk. Hal ini terjadi diakibatkan karena masih banyak para nakhoda tidak memahami tanda-tanda meteorologi yang disampaikan oleh Badan Meteorologi, Klimatologi dan Geofisika (BMKG) terutama tentang membaca peta cuaca.

Tujuan penelitian ini diharapkan bahwa para nakhoda dapat memahami atau membaca weather chart dan dapat menentukan daerah cuaca buruk, sehingga para nakhoda jangan sampai terjebak pada daerah cuaca buruk tersebut dan dapat mengambil langkah-langkah menghindari daerah cuaca buruk supaya dalam menjalankan kapalnya selamat sampai tujuan.

Hal-hal yang perlu diperhatikan nakhoda saat melaksanakan pelayaran adalah sebagai berikut: 
1. Awan Cumulonimbus (Cb)

Awan Cumulonimbus yang merupakan salah satu jenis awan konvektif yang banyak diketahui. Awan Cumulonimbus yang dapat menimbulkan berbagai fenomena cuaca ekstrim seperti angin kencang, hujan lebat, badai guntur, puting beliung, dan lain-lain. Awan ini tumbuh secara vertikal dengan tinggi dasar umumnya kurang dari 1000 meter dan tinggi puncak mencapai 50.000 kaki. Awan Cumulonimbus dapat terbentuk dari turbulensi permukaan, namun dapat juga terbentuk karena pola angin konvergen, daerah front, dan lainlain. (Ribudiyanto dan Sucahyono, 2013).

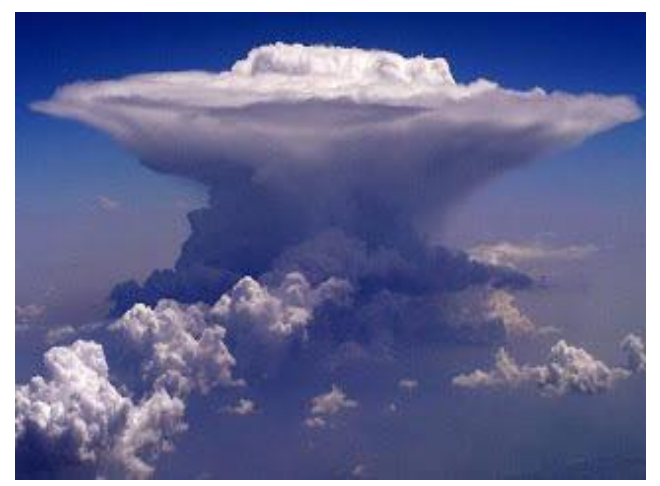

Sumber: Liputan6.com

Gambar 1. Awan Cumulo Nimbus (Cb)

2. Tekanan Udara

Tekanan udara adalah gaya berat kolom udara dari permukaan tanah sampai puncak atmosfer per satuan luas, Gaya ini ditimbulkan oleh percepatan ke bawah beruba gravitasi dan massa udara. Hasil perkalian keduanya disebut berat, oleh karena itu tekanan udara pada setiap titik merupakan berat total udara di atas titik tersebut per satuan luas (Paulus AW, 2010)

Sel tekanan tinggi $(\mathrm{H})$ adalah daerah yang mempunyai tekanan udara paling tinggi dibandingkan dengan sekelilingnya. Makin ke pusat, tekanan udaranya makin tinggi. Sistem anginnya anti siklonik kondisi cuaca cerah.

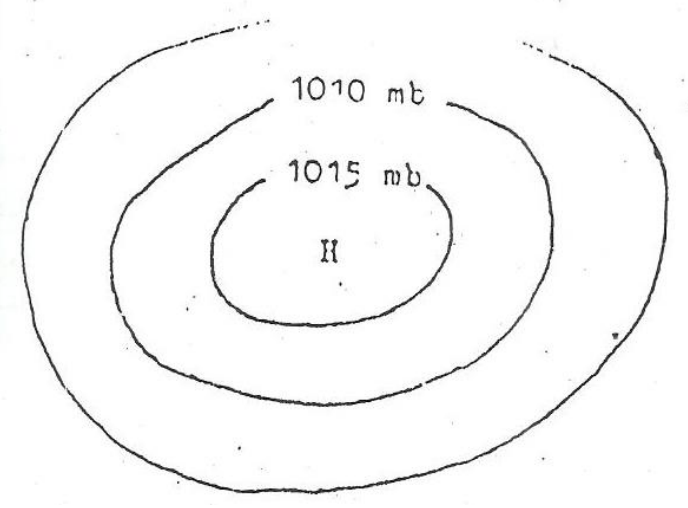

Gambar 2. High Pressure (H)

Sel tekanan rendah (L) adalah daerah yang mempunyai tekanan udara paling rendah dibandingkan dengan sekelilingnya, makin ke pusat tekanan udaranya makin rendah, sistem anginnya siklonik. Kondisi cuaca berawan banyak awan yang terbentuk awan Cumulonimbus $(\mathrm{Cb})$.

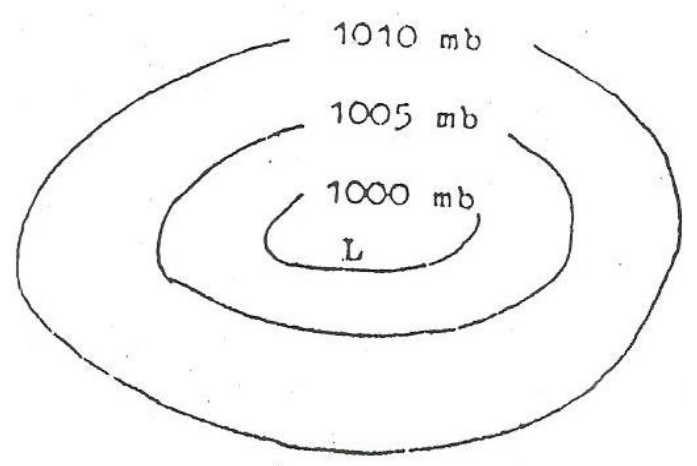

Gambar 3. Low Pressure (L)

\section{Front Cuaca}

Front cuaca adalah bidang pertemuan antara massa udara panas dengan massa udara dingin. Awan yang terbentuk awan konvektif seperti awan Cumulonimbus (Cb), Cumulo Congestus (Furcon Alfahmi, 2013)

Daerah tersebut kondisi cuaca berawan banyak terutama awan Cumulonimbus (Cb) yang dapat menimbulkan thunderstorm yang dapat 
menyebabkan hujan lebat badai petir dan guntur serta angin kencang

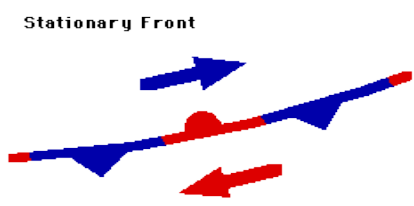

Gambar 4. Front

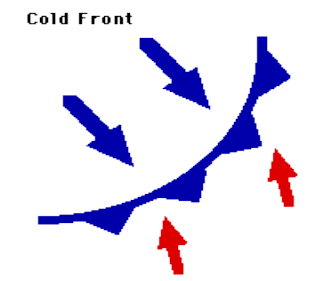

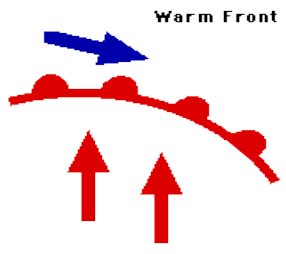

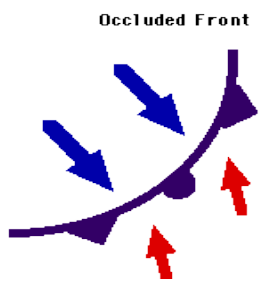

\section{Tropical Siklon}

Tropical siklon adalah sistem angin pusaran yang melanda daerah pusat tekanan rendah atmosfer (Low Pressure) lalu bergerak ribuan kilometer ke pantai di sekitarnya. Di Atlantik dan Caribia diperkirakan 10 topan terjadi setiap tahunnya selama 75 tahun pertama diantara lintang $23.5^{\circ} \mathrm{LU}-23.5^{\circ} \mathrm{LS}$ kadang-kadang meluas sampai lintang $30^{\circ}$ LU $-30^{\circ}$ LS Kondisi cuacanya daerah Tropical Siklon adalah berawan banyak umumnya awan Cumulo Nimbus (Cb) hujan lebat disertai badai Guntur petir angin berputar-putar dengan ecepatan diatas 100 Knots. ( Suryadi WH, 2015).

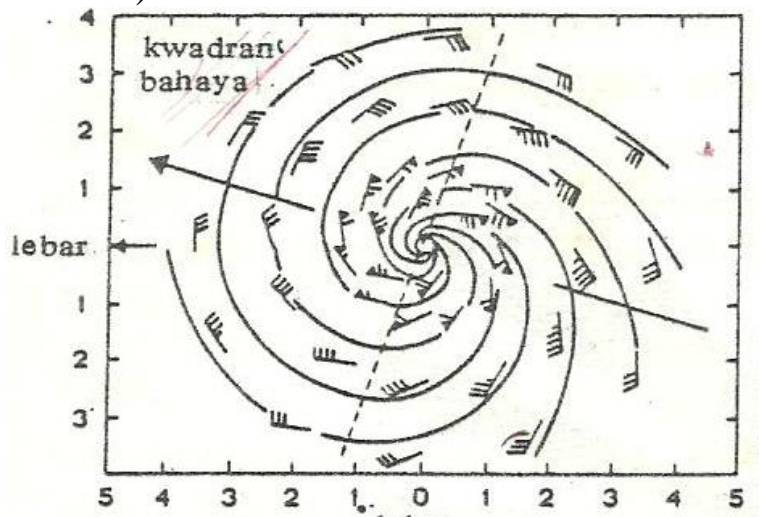

Sumber: Vanderham, 1980

Gambar 5. Angin Siklon Tropic Di Belahan Bumi Utara

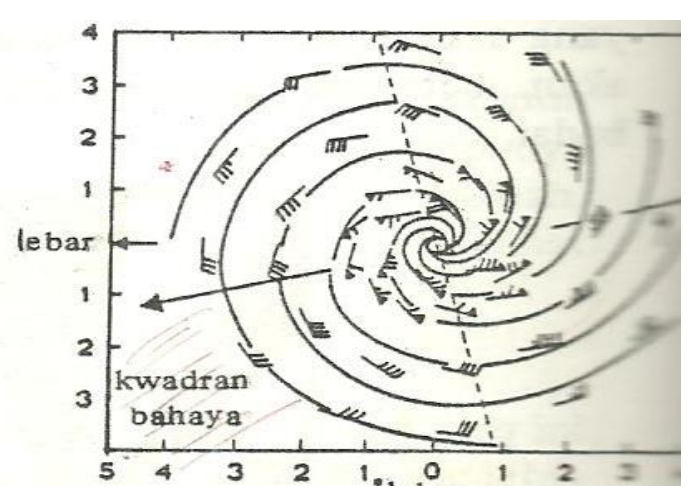

Sumber: Vanderham, 1980

Gambar 6. Angin Siklon Tropis di Belahan Bumi Selatan

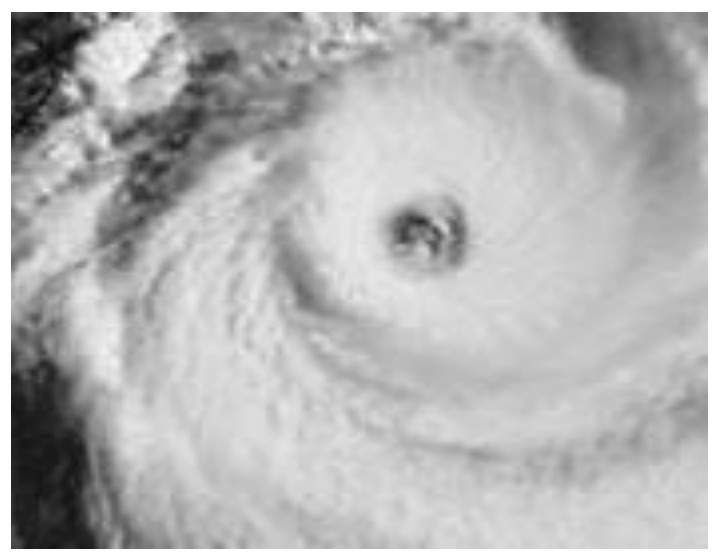

Sumber: gettyimages.com

Gambar 7. Siklon Tropis

\section{Convergence}

Convergence merupakan daerah pertemuan antara dua massa udara membentuk suatu gugusan memanjang apabila dua massa udara tersebut berasal dari samodra atau lautan yang sifatnya basah akan terbentuk banyak awan yang dapat menimbulkan hujan (Handoko, 2010)

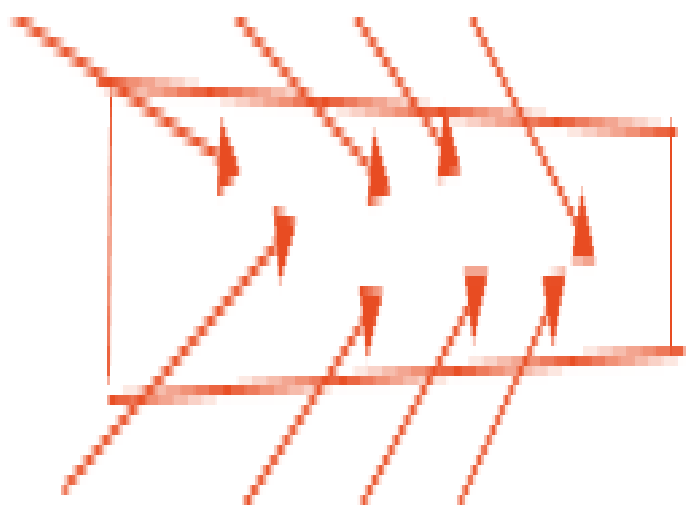

Gambar 8. Convergence 


\section{METODE}

Penelitian ini merupakan penelitian deskriptif kualitatif diman metode yang dipakai studi pustaka dan pengamatan. Di mana penelitian ini banyak mengambil referensi-referensi dari buku literasi dan website-website cuaca seperti bmkg.go.id. dan pengamtan secara empiris yang telah pernah dialami penulis.

\section{HASIL DAN PEMBAHASAN}

Di dalam menentukan daerah cuaca buruk perlu dilakukan terlebih dahulu dengan melakukan analisa dalam bentuk weather chart. Analisa tersebut dapat dilakukan dengan beberapa cara antara lain:

1. Analisa Isobar

Isobar adalah garis menghubungkan daerah daerah yang mempunyai tekanan udara yang sama, dalam analisa isobar akan terbentuk sel Tekanan Rendah (Low Pressure) dan Sel Tekanan Tinggi (High Pressure).

Sel Tekanan Rendah (L) simbol di tulis adalah daerah yang mempunyai tekanan udara paling rendah dari pada sekitarnya. Sirkulasi anginnya siklonik, suhunya tinggi, kondisi cuaca berawan banyak deangan awan Cumulonimbus (Cb) disertai hujan dan badai Guntur dan angin kencang. Sedangkan sel tekanan tinggi (high pressure) daerah yang mempunyai tekanan udara paling tinggi dari sekitarnya, kondisi cuaca cerah dengan suhu rendah

Front cuaca adalah bidang pertemuan antara massa udara panas dengan massa udara dingin. Daerah tersebut kondisi cuaca berawan banyak terutama awan Cumulonimbus (Cb) yang dapat menimbulkan Thunderstorm yang dapat menyebabkan hujan lebat badai petir dan guntur serta angin kencang

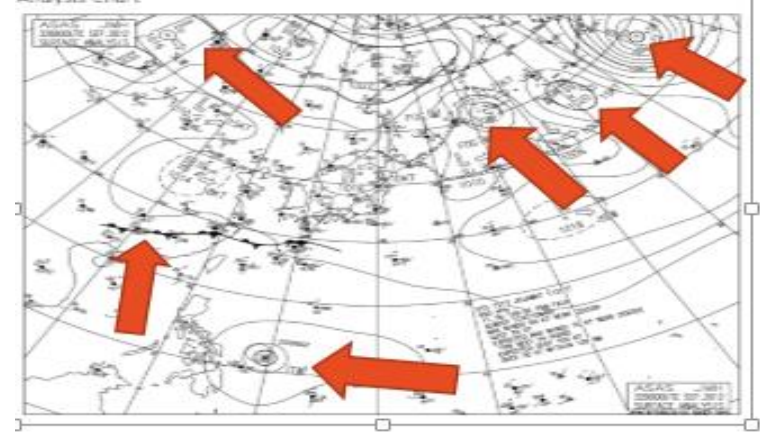

Sumber: bmkg..go.id

Gambar 9. Analisa Isobar

Keterangan: Tanda panah menunjukan adanya L (low pressure), Front dan Siklon Tropis daerah tersebut kondisi cuacanya buruk. Awannya awan konvektif seperti awan Cumulonimbus $(\mathrm{Cb})$.

2. Analisa Streamline dan Isotach

Streamline adalah garis yang menghubungkan daerah-daerah yang mempunyai arah angin yang sama. Isotach adalah garis yang menghubungkan daerah daerah yang mempunyai kecepatan angin yang sama. Di dalam analisa streamline terdapat. Angin siklonic (adanya low pressure) apabila tekanan tendah tekanannya udaranya turun drastis (falling sharp) yang dapat menjadi topan maka kondisi cuacanya angin yang berputar-putar dengan kecepatan yang kuat sekali diatas 60 knots banyak awan Cumulonimbus $(\mathrm{Cb})$ yang menimbulkan hujan lebat badai guntur dan petir disertai gelombang laut hingga tingginya mencapai $10 \mathrm{M}$.

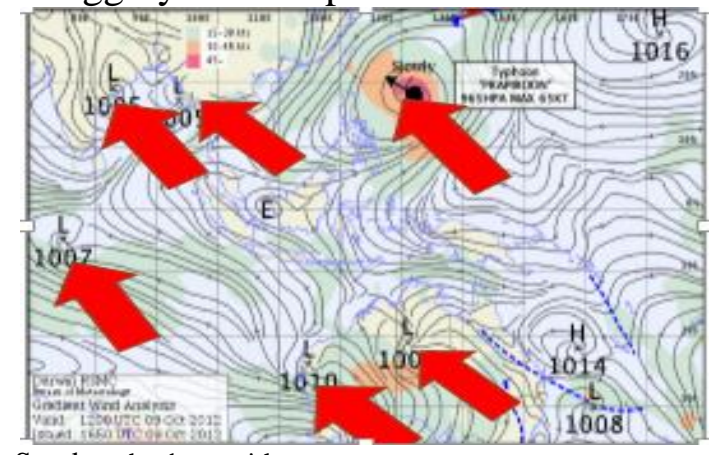

Sumber: bmkg..go.id

Gambar 10. Streamline dan isotach 
Keterangan: Gambar panah menunjukkan siklonik pada daerah Tekanan rendah dan Siklon Tropis

Daerah Konvergensi (convergence) adalah garis yang bertemu membentuk daerah convergence dua massa udara apabila udara tersebut dari dua samodra, pada daerah tersebut terbentuk awan banyak diantaranya tumbuh awan Cumulus dan Cumulonimbus (Cb) dan dapat menimbulkan hujan lebat, badai guntur, petir dan angin kencang.

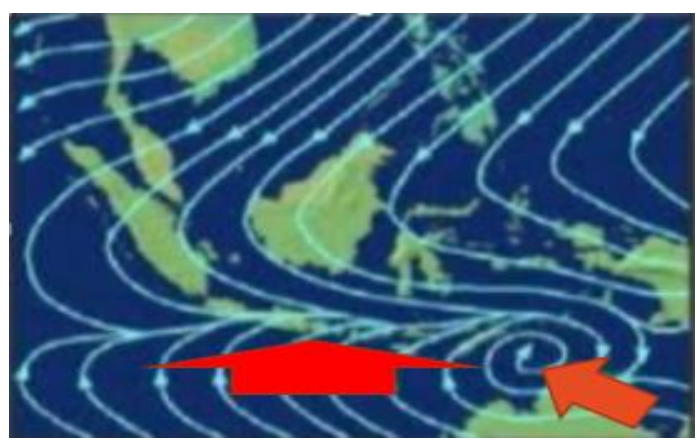

Sumber: bmkg..go.id

Gambar 10. Analisa Streamline

Keterangan: Gambar panah menunjukkan daerah convergence dan siklonik (daerah Low Pressue).

3. Analisa satelit awan

Dari hasil analisa awan terlihat jelas bahwa daerah cuaca buruk terlihat awannya banyak dan tebal karena awan yang terbentuk adalah awan-awan Cumulonimbus (Cb) yang dapat menimbulkan thunderstorm dimana terjadi hujan lebat badai petir, badai guntur serta angin kencang.

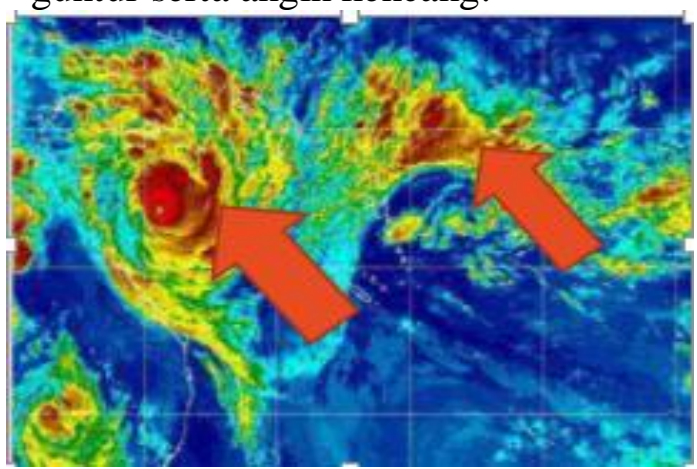

Sumber: bmkg..go.id

Gambar 11. Satelit Image
Keterangan: Gambar panah awan tebal pada siklon tropis dan siklonik pada daerah low pressure.

\section{Analisa Isohume.}

Isohume adalah garis yang menghubungkan daerah daerah yang mempunyai kelembaban udara yang sama. Dari hasil analisa isohume terlihat daerah daerah yang cuaca buruk yang mempunyai kelembaban tinggi, dengan kelembaban tinggi berarti awannya banyak.

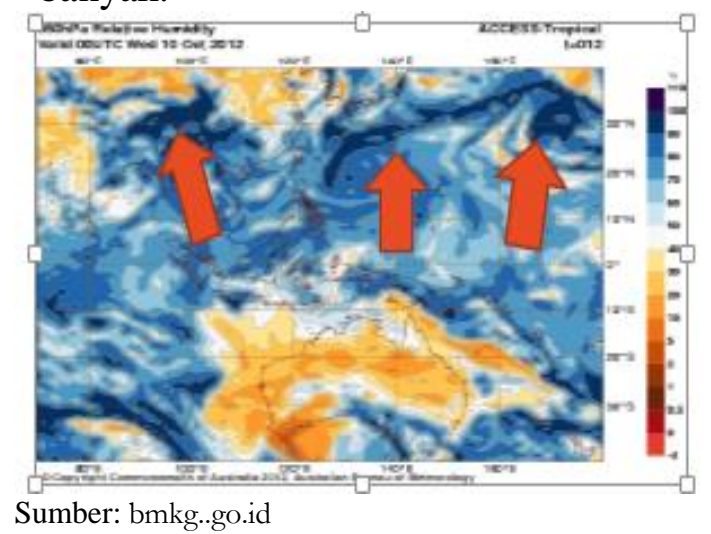

Gambar 12. Analisa Isohume

Keterangan: Gambar panah kelembabannya tinggi berarti banyak awan dan hujan

5. Analisa Isocurrent

Isocurrent adalah garis yang menghubungkan daerah daerah yang mempunyai kecepatan arus laut yang sama, pada isocurrent tingkatan kecepatannya digambarkan dengan warna.

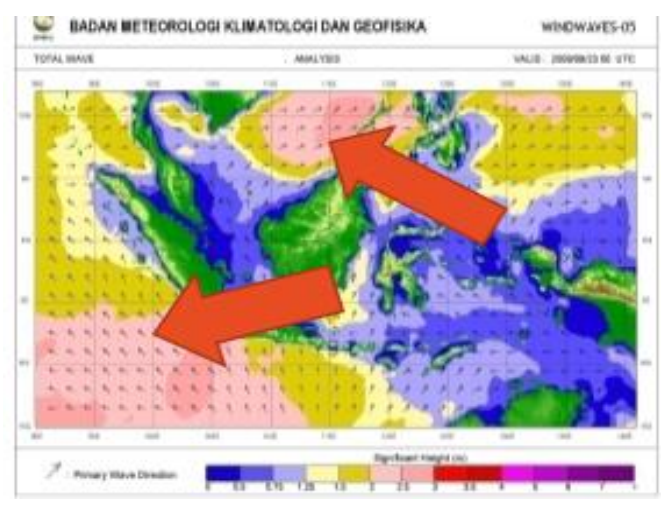

Sumber: bmkg..go.id

Gambar 13. Isocurrent 
Keterangan: Gambar panah mennjukan daerah yang kecepatan arus lautnya tinggi diatas 40 knots.

6. Analisa Isowave

Isowave adalah garis yang menghubungkan daerah daerah yang mempunyai tinggi gelombang laut yang sama.

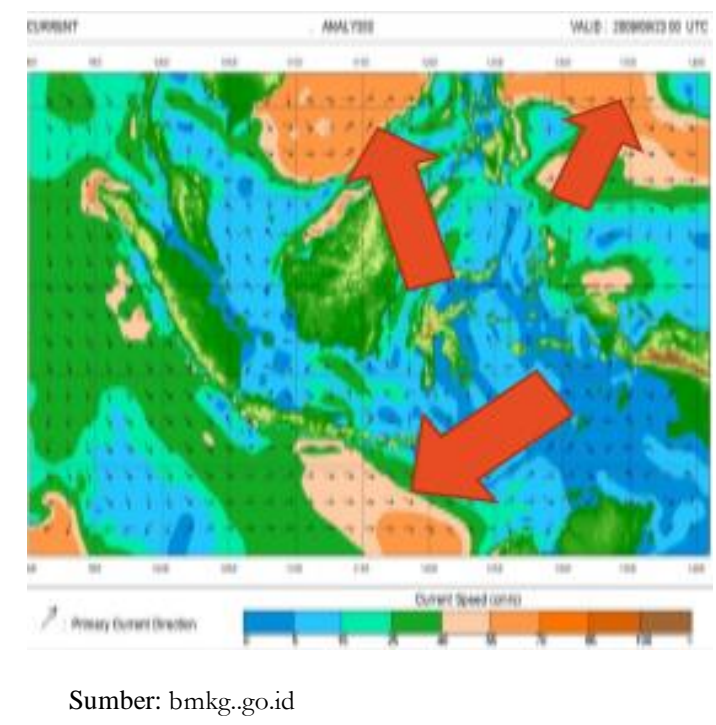

Gambar 14. Isowave

Keterangan: Tanda panah menunjukkan daerah yang gelombang lautnya tinggi.

\section{SIMPULAN}

Kondisi cuaca setelah dianalisa setiap unsur cuaca dapat ditentukan pada daerah cuaca buruk atau baik setelah digambar dalam bentuk analisa pada weather chart dengan simbol akan jelas terlihat dalam seperti daerah-daerah; low pressure (L), konvergence, siklonik, front, tinggi gelombang, kelembaban udara.

Kepada para calon nakhoda atau para nakhoda untuk dapat memahami simbolsimbol meteorologi mengenai daerah cuaca buruk.

\section{DAFTAR PUSTAKA}

C.J.Vanderham, 1980 Meteorologi dan Oceanografi untuk Pelayaran, Alih bahasa PT.Triasko Madra Dirjen Perhubungan Laut Jakarta.

Furqon, 2013, Cuaca Sub Tropic Seminar, BMKG Jakarta

Handoko, 2013, Meteorologi Dasar. Pustaka Jaya: Bogor.

Paulus AW 2010, Meteorologi dan Turbulensi Jurnal BMKG Jakarta

Ribudiyanto, 2013, Awan Cumulo Nimbus dan Dampaknya IPB Bogor

Suryadi WH, 2015, Tropical cyclone dan dampaknya di Indonesia BMKG Jakarta.

Soepangkat, 1991, Pengantar Meteorologi dan Oceanografi AMG Jakarta.

Soeharsono. 1976. Pengamatan Meteorologi BMG Jakarta. 